\title{
A Study on the Predicaments and Innovative Outlet of Applying Finance Guarantee Tools in the Rural Areas
}

\author{
Yinan Guo, Jing Fan, Jinglong Li \\ ${ }^{1}$ School of Economics and Management, Jilin Agricultural University, Changchun, Jilin, China \\ ${ }^{2}$ School of Economics and Management, Jilin Agricultural University, Changchun, Jilin, China \\ ${ }^{3}$ School of Economics and Management, Jilin Agricultural University, Changchun, Jilin, China \\ agyncn@163.com, b 851583644@qq.com, c lj1574@163.com
}

Keywords: Rural finance, Guarantee instrument, Collateral

\begin{abstract}
The developing of agricultural industry is still lag in china, comparing with other industries. Three issues concerning "Countryside, agriculture, peasant" have increasingly become the bottle-neck, restricting the national economic development and people's income growth. The fund has become the weakness of agricultural development under favorable factors of good national policies and technical innovation. The rural land property rights system of China has some specific characteristics. The ownership and the user of land are separated, which cause farmers find it difficult to get loans by mortgaging on land. This article analyzes the mortgage difficulties in Chinese rural areas and puts forwards the innovative tools to perfect guarantee system, hoping for providing some suggestions for solving rural financial predicament.
\end{abstract}

In order to solve the problems of agriculture, Chinese government has issued the central document No.1 concerning "Countryside, agriculture, peasant" to make specific deploy to the rural reform and agricultural development from 1982 to 1986. The central document No.1 concerning "three rural" has released for eleven consecutive years, which stress the "priority among priorities" status of "three rural issues" in the China socialist modernization period from 2004 to 2014.

No. 1 documents in 2013 suggested that transforming the contracted land into professional investors, family farm and farmer cooperatives was encouraged and supported. Among them, the concept of "family farm" is first appeared in the central document. No. 1 documents in 2014 determined that further emancipating the mind, advancing steadily, reforming and innovation, and resolutely getting rid of mechanism drawbacks, adhering to the fundamental position of agriculture, speeding up the modernization of agriculture. As everyone knows, "farmers" is the core of "three rural" issue, the key to solve the problem of farmers is the effective treatment of land problem. For a long time, the land and the farmers have a natural link, rural land is not only an important income of the farmers, but also plays the role of social security to a certain extent; it is the fundament of farmers' survival and rural economic development.

\section{The urgency of the rural financial guarantee tool innovation}

Since the reform and opening up, Chinese economy has experienced thirty years of strong growth, during these years, Chinese government has also introduced a series of policies aimed at stimulating food production, stabilizing the enthusiasm of the farmers. But Chinese food pricing system has long been combined national regulation with market forces, which is not compatible with agricultural and other industrial products. The food price rises behind the agricultural commodity prices rise. With the development of rural economy, Market allocation of agricultural production factors caused the flowing of the rural labor force, land and other resources to the more comparative advantage industry, service industry and other fields, which damaged the rural areas and farmers' interests in essence.

Due to the imbalanced development and dualistic economic structure, the gap between urban and rural areas is significant," three rural issues" becomes more prominent----the agricultural development remain stagnant, the rural economy is in trouble, farmers' income increases slowly, 
farmers once fall into financial difficulties, there is a serious imbalance between supply and demand of rural financial. Under this situation, the government has taken various measures, there has been some improvement, but the effect is not significant. Although the exemption of agricultural tax and grain subsidies stimulated the enthusiasm of farmers and reduced the burden of farmers to a certain extent, farmers' income channel remain unchanged.

Land is one of the most basic factors of production and it is also the largest and most valuable resource that farmers can use. How to enliven the land assets and broaden sources of income for farmers? It is a question that is worthy of our consideration. Regarding the rural land reform as a breakthrough point, combining the land and finance, and then constructing rural land financial system, maybe that is a good idea to solve "three rural issues ". In the practice of agricultural development in the world, rural land financial system, as an inseparable part of rural financial system, has been shown to play an extremely important role in the rural land resource allocation of agricultural credit, investment, agricultural efficiency and competitiveness. For our country, the study of rural land finance is in continuous exploration, either in theory or in practice. It has not formed a complete system yet. So it is necessary to combine with China's specific national conditions, proceed from reality to construct a rural land financial system of our own.

The development of rural economy lags behind the city, the financial development is weaker. According to statistics, by the end of 2012, rural credit was less than 1/10 of all, and the gap is widening, which shows that rural finance improves slowly in both quantity and quality. One of the important reasons for the slow increase of total rural credit is the shortage of collateral, which has become an important bottleneck of small and medium-sized enterprises and the "three rural" financing.

\section{Predicaments of applying finance guarantee tools in the rural areas}

Guarantee mode has innovated, the way to guarantee extended to use part of the ownership, use rights, property rights guarantee, also appeared a variety of combined collateral in the guarantee. Guarantee innovation has important significance for expanding financial services and increasing the depth of financial services. But it still has many shortcomings, which embody in the following areas:

\subsection{Implementation of the operation}

\subsubsection{Imperfect legal basis}

One principle of "Property law" is property announcement. The principle of real right, namely the right alteration must be displayed in an objective way in order to gain social and legal recognition. However, property registration in China has the phenomenon of management department crossing, such as the forest property rights and land use rights guarantee. In accordance with the provisions of "security law", forest rights for guarantee shall be subject to the approval of the competent forestry department at the county level or above, and land use rights guaranteed should be registered by local land department. The issue of cross sectors and even subordinate department approval at the same time, which will undoubtedly increase the operation process and improve operational costs.

\subsubsection{Lack of fair intermediary organization}

In the survey, cases rely on credit rating, assets evaluation; credit guarantee of the intermediary organizations are rare. Lack of intermediary organizations causes banks to bear too much functions of information processing. From the microscopic point of view, the main reason of lacking intermediary organizations is that the forms of monopoly of the financial industry make the professional division of labor can not go deeply, which occupies the market position of intermediary organization. In addition, the legal and social environment protection is not sufficient, the intermediary organization parasites on financial institutions and government departments, so it could not make an objective evaluation on the information.

\subsubsection{High real interest rates}


Through investigation we found that enterprises adopting innovative guarantee security, they generally pay $10 \%-30 \%$ higher than normal rates. real interest rates are above $7 \%$.Banks have to take greater risks, so it is reasonable for them to raise interest rate, but for the farmers, the burden of debt servicing is increasing, which prevents guarantee innovation from carrying out broadly. Considering the security innovation generally appears in the "three rural" financing, high interest rates are clearly inconsistent with national support policies.

\subsubsection{Lack of the unified operating procedures}

Because the immovable property and usufruct guarantee are still in the stage of exploration and innovation, the operation procedure is lack of unity, which becomes the main factor restricting the popularization and application of security innovation. Almost every case has its own set of operating procedures, some rely on intermediaries to assess the value of the security, some rely on regulators to supervise the guaranty, but in most cases the financial institutions do the job of assessment and managed. In the face of inaccurate statistics and management of inventory, financial institution is unable to deal with. Therefore, lacking of the unified operating procedures is an important factor affecting the guarantee effect.

\subsection{The financial risk control}

\subsubsection{The subject-matter of security Innovation contract changes frequently}

The form and nature of usufruct may be changing especially when it is using, transferring and changing .For banks, existing form of collateral has changed, that is, collateral becomes less stable, which results in market risk. For example, in the case of the mortgage of land contract management right, bank has to track the actual usage of the land in order to ensure the actual circumstances of collateral. Another example, getting loan by Land use rights guarantee and then subcontract. After borrowers obtain loans, the subcontractors cultivate the land then the second change of land use rights is bound to occur. If the estate is not repaid in time, repayment must be involved in the use rights and appendage of subcontracting, which will cause trouble for the banks.

\subsubsection{Larger loopholes in collateral valuation and trusteeship}

Local financial institutions have no ability to calculate real right of pledge according to the market changes, resulting in the short credit period, which is the direct cause that the short term credit accounted for the majority. On the other hand, Collateral trusts generally take the financing party to the contract managed or managed, and the third party hosting is less. The financing party hosted will result in no divided power, no timely tracking; in fact it is easy to cause collateral loss and damage, which damage the interests of financial institutions.

\section{Applications of China's rural credit guarantee mortgage}

Financing bottleneck and problems of guarantee mortgages in rural cause the secured mortgage innovation, it becomes the focus of rural finance. Guarantee innovation can be done in two ways: expanding the scope of collateral and innovation of guarantee way. The formers have the property and the creditor's rights guarantee, such as all kinds of raw materials, inventory, accounts receivable, accounts receivable factoring etc., The latter is mainly for the real guarantee, such as motor vehicles, farmers have the right to use the land, farmers pigs and other livestock.

\subsection{Usufructuary right guarantee}

The usufructuary right, which refers to the exclusive rights that an non-owner has enjoy, possess, use, and make profits, including the right to the contracted management of land, $t$ use Homestead Land, easement, natural resources etc., while forest right, mining right, wasteland development belong to the right of using natural resources. "The property law" will play a great role in promoting the development of usufructuary right guarantee. A number of cases of the forest right, mining right, and land use right and so on appear in many regions. Which has large amount of financing, flexible, and it can even adopt installment payment. The advantages of using usufructuary right as guarantee collateral are as followed: it does not occupy the real property of financing party, not affect the 
enterprise's production process. Therefore, it has flexible financing rates and the amount is varied. Disadvantages: professional organizations are needed to evaluate and identify, and even government departments are needed, procedures are complicated, so it is not conducive to implement.

\subsection{Agricultural products guarantee}

Agricultural products guarantee is one of the less used forms of rural security Innovation at present, such as planting commodity grain security, breeding herds' pigs guarantee. And banks mainly perform the following three aspects of the procedure: firstly, according to farmers' original information to classify the rate credit and decide whether to grant financial support. Secondly, audit process of the collateral, including: the collateral investigation, evaluation, insurance, warehousing. Thirdly, the credit procedures for examination, approval and contract after the disposal of collateral are adopted. This kind of guarantee loan is relevant to assessment price of stock.

\subsection{Credit guarantee provided by other financial intermediaries}

One of the difficulties that guarantee innovation face is the lack of specialized agencies to improve the problem of asymmetric information between borrowers and financial institutions and reduce the information cost of financing both sides. Financing with guarantee agencies, on the one hand, guarantee institutions could provide quality assurance for the financing party, on the other hand, they can provide counter guarantee for collateral, strengthen the credibility and guarantee ability. However, in practice, few farmers use financing institutions to guarantee.

\subsection{Joint guarantee}

Combination type of guarantee is mainly divided into two categories: one is the joint guarantee rely on reputation, two is the combined use of the above single secured loan guarantee form. These two kinds of amount is generally small, generally apply to small and medium farmers financing. Because the small and medium-sized farmers are lack of valuable collateral, and for the banks, simplifying procedures and reducing cost will provide living space for the joint guarantee, such as the agricultural products processing enterprise "enterprise + farmer" type connected guarantee. Inventory guarantee that production enterprise applied from the local agricultural development bank and accounts-receivable guarantee belong to the inventory and accounts receivable combined guarantee.

\subsection{Accounts receivable guarantee and factoring business}

Accounts receivable secured refers to the financing way with recourse accounts receivable vouchers, According to the "security law", it could not be transferred without consultation when accounts receivable provide guarantee. But factoring business is different. It can also provide the guarantee as accounts receivable to a certain extent. The difference is that the guarantee certificate transfer to the financial intermediary, who is responsible for due payment, which essentially constitute the buyer, the seller and the three party contract relationship. Financing amount of accounts receivable is related to the receivable amount. The more complicated factoring business usually involves larger amounts, generally for a period of a production and sales cycle. This kind of financing way plays a great role in solving the much-needed funds of the family farm.

\section{Summary}

The mortgage innovation of rural credit guarantee in its essence is the reasonable demand for the bottleneck of financial services in rural areas at the present stage; the implementation of "property law" creates a good environment for guarantee mortgage innovation in the rural area. But in the premise of the reasonable demands cannot be solved, innovation represents the future orientation. Therefore, it needs further strength and depth. We need continue to improve the legal system, speed up financial reform, increase security innovation support from the macro level, and continue to strengthen the role financial intermediary organizations play in the guarantee innovation. Consider social intangible assets such as personal qualification, social consensus etc, as guarantee withstand 
high category and open channels for breakthrough the financing bottleneck in order to make contributions to the fund bottleneck to solve the three rural problems.

\section{References}

[1] Information on http://www.famer.com.cn

[2] Leat, P., Revoredo Giha, C.: Building collaborative agri-food supply chains [J]. British Food Journal, (2008), 110 (4-5):395-411.

[3] Rui Albuquerque, Hugo A. Hopenhayn: Optimal Lending Contracts and Firm Dynamics, Review of Economic studies, (2004), Vo1.71:285-315.

[4] Newbery, David M. G and Joseph E. Stiglitz: The Theory of Commodity Price Stabilization: A Study in the Economics of Risk [M]. New York: Clarendon Press. (1981).

[5] Hishigsuren, G: Evaluating Mission Drift in Microfinance: Lessons for Programs with Social Mission, Evaluation Review,( 2007), 31(3):203 - 260. 